\title{
Risk of severe hypoglycaemia in insulin treated diabetic patients transferred to human insulin: a case control study
}

\author{
Matthias Egger, George Davey Smith, Hans Imhoof, Arthur Teuscher
}

\begin{abstract}
Objective-To examine whether transfer from animal insulin to human insulin is associated with an increased risk of severe hypoglycaemia.

Design-Matched case-control study of insulin treated diabetic patients admitted to hospital because of hypoglycaemia during 1984-7, the period when human insulin was introduced into treatment.
\end{abstract}

Setting-Case admissions and control admissions were obtained from eight public hospitals within the Swiss canton of Berne and a second control group comprised members of the Bernese section of the Swiss Diabetes Association.

Subjects -94 patients with insulin treated diabetes with a total of 112 admissions for hypoglycaemia during 1984-7 (case admissions), 182 patients with insulin treated diabetes seen in the same hospitals for reasons other than hypoglycaemia with a total of 225 admissions (control admissions), and 86 insulin treated diabetic patients who were members of the Bernese section of the Swiss Diabetes Association.

Main outcome measures-Type of insulin used at time of admission, glycaemic control as measured by amount of glycated haemoglobin or glucose concentration; severity of hypoglycaemia.

Results-Treatment with human insulin at admission was more common in cases than controls $(52 / 112(46 \%)$ admissions $v 77 / 225(34 \%) ; \mathrm{p}=0.003)$. 116 out of $129(90 \%)$ of admissions taking human insulin had been transferred from animal insulin, mainly because of non-availability of porcine insulins. The ratio of rate of hypoglycaemia in those taking human insulin to the rate in those taking animal insulin was 2.4 (95\% confidence interval 1.3 to $4 \cdot 4$ ). Other risk factors for hypoglycaemia were a history of hypoglycaemic coma (rate ratio of history to no history $3.8,2.3$ to 6.4 ) and good glycaemic control (rate ratio of good to poor control 3.9, 1.4 to $7 \cdot 5)$. With multivariate analysis the increase in rate ratio associated with use of human insulin rose to 3.0 $(1.4$ to 6.4). Comparison with the diabetes association controls also showed an increased risk associated with use of human insulin $(2 \cdot 2 ; 1 \cdot 1$ to $4 \cdot 8)$.

Conclusions - Transfer of treatment from animal insulin to human insulin was associated with an increased risk of severe hypoglycaemia. Caution should be exercised when transferring diabetic patients to human insulin. Further studies are required to elucidate why this effect occurs.

\section{Introduction}

Human insulins of recombinant DNA origin and semisynthetic human insulins manufactured from porcine insulin became available in Switzerland in 1983. They were not widely used until 1986, when two porcine preparations (Actrapid and Monotard Novo) were withdrawn and replaced by human preparations. Table I shows the annual increase in use of human insulin from 1984 to 1987.

Impaired recognition of hypoglycaemia in diabetic patients transferred from animal insulin to human insulin was first reported from retrospective clinical surveys. ${ }^{12}$ Reduced awareness of hypoglycaemia could lead to patients failing to take evasive action, with a consequent increased risk of progression to severe hypoglycaemia. The patients in these clinical series may, however, have developed impaired awareness of hypoglycaemia with time, irrespective of transfer to human insulin.

Subsequent work suggested that there could be a real difference in response to human and porcine insulin ${ }^{4} ;$ consequently, prospective randomised clinical trials have been advocated to clarify this issue. ${ }^{6}$ Such a trial would be a major undertaking, as the sample size requirements are considerable. For example, to detect a doubling of the risk of severe hypoglycaemia, assuming $5 \%$ of patients have one episode each year, about 1160 patients would have to be followed up for one year.

Case-control studies require smaller sample sizes than prospective studies and can be completed in a shorter period of time. ${ }^{8}$ Case-control studies on this topic, however, are susceptible to bias if patients at high risk of hypoglycaemia were more likely to be transferred to human insulin. In Switzerland this was generally not the case because most patients were transferred to human insulin between 1984 and 1987 simply because porcine insulins became unavailable. We performed a case-control study of all patients with hypoglycaemia admitted to eight hospitals in the canton of Berne, Switzerland between 1984 and 1987.

\section{Patients and methods}

\section{STUDY DESIGN AND DEFINITIONS}

Cases and controls were identified from a computerised database (VESKA-Statistik ${ }^{9}$, which holds data on all patients admitted to 139 Swiss hospitals. The first visit of patients attending an outpatient clinic is also recorded. For each patient up to 10 diagnoses are coded according to the ICD ninth revision. Eight public hospitals in the canton of Berne (with 928000 inhabitants in 1985) contribute to the VESKA-Statistik system, and all participated in our study. These included all three university hospitals (Inselspital, Tiefenauspital, and Zieglerspital), three regional hospitals (Interlaken, Langenthal, and Thun), and two district hospitals (Grosshöchstetten and Niederbipp). These hospitals recorded $57 \cdot 5 \%$ of all hospital admissions in the canton in 1987.

Case admissions were defined as admissions for hypoglycaemia of insulin treated diabetic patients aged 16 to 90 years to one of the eight study hospitals from 1 January 1984 to 31 December 1987. Patients treated in an emergency ward and discharged on the same day were also included. The ICD (ninth revision) codes for "hypoglycaemic coma" (251.0) and "hypoglycaemia unspecified" $(251 \cdot 2)$ were used to identify case admissions. Although the code $250 \cdot 2$ ("diabetes with coma") applies to ketoacidotic or hyperosmolar coma, admissions for hypoglycaemic coma could be misclassified into this group. Therefore, hospital records for every admission with code $250 \cdot 2$ were also examined, and any misclassified admissions for hypoglycaemia were included. 
Control admissions were chosen from among insulin treated diabetic patients admitted to the study hospitals or seen in outpatient clinics for conditions other than hypoglycaemia. The ICD codes do not distinguish between insulin treated diabetes and non-insulin treated diabetes. Out of lists of all potential control admissions, which included sex and age of the patient and date of admission, matched controls were consecutively selected until two insulin treated controls were identified for each case. Age was matched within four age strata: $16-29,30-49,50-69$, and 70-90 years.

Exposure to human insulin was defined as use of any human insulin, semisynthetic or genetically engineered, at the time of hospital admission.

Blood glucose control-Glycated haemoglobin $A_{1}$ values (Microcolumn Boehringer, reference 5·1-8.0\%) were available for 94 (28\%) of admissions, and glycated haemoglobin $\mathrm{A}_{1 \mathrm{c}}$ values (Biorad, reference 3.4-6.1\%) for $69(20 \%)$. For $174(52 \%)$ of the admissions glycaemic control was assessed by using a mean number of $5 \cdot 5$ (range 3-60) blood glucose values determined before admission. Blood glucose control was classified according to recommendations of the American Diabetes Association ${ }^{10}$ as "good" if mean amount of glycated haemoglobin $A_{1}\left(A_{1 c}\right)$ was $\leqslant 8 \%(\leqslant 6 \%)$ or mean blood glucose concentration was $\leqslant 7 \mathrm{mmol} / \mathrm{l}$; "acceptable" if glycated haemoglobin $A_{1}\left(A_{1 c}\right)$ was $>8 \%(>6 \%)$ and $\leqslant 10 \%(\leqslant 7 \cdot 5 \%)$ or mean blood glucose was $>7 \mathrm{mmol}$ and $\leqslant 10 \mathrm{mmol} / \mathrm{l}$; "fair" if glycated haemoglobin $\mathrm{A}_{1}$ $\left(\mathrm{A}_{1 \mathrm{c}}\right)$ was $>10 \%(>7 \cdot 5 \%)$ and $\leqslant 12 \%(\leqslant 9 \%)$ or mean blood glucose was $>10 \mathrm{mmol}$ and $\leqslant 13 \mathrm{mmol} / 1$; and "poor" if glycated haemoglobin $\mathrm{A}_{1}\left(\mathrm{~A}_{\mathrm{lc}}\right)$ was $>12 \%$ $(>9 \%)$ or mean blood glucose was $>13 \mathrm{mmol} / \mathrm{l}$.

Onset of diabetes was defined as early if first diagnosed before the age of 30 years and late if diagnosed at or after age 30.

Data collection-Data regarding exposure to human insulin and clinical variables were obtained from hospital records and from a standardised questionnaire, which was sent to the family doctors. Files from health insurance companies and pharmacies were also used to determine whether the human or the porcine preparation of insulin was used.

Swiss Diabetes Association controls-To assess whether differential admission rates for the controls' conditions between patients treated with animal insulin and those treated with human insulin could bias the comparison with the hospital controls ${ }^{11}$ a second control group was investigated. This group was chosen from the membership files of the Bernese section of the Swiss Diabetes Association, which has 1600 members -about $30 \%$ of all insulin treated diabetic patients in the canton. Two association controls were matched to each case admitted during 1987. Matching was by sex and age, with the same age strata as for hospital controls. Information relating to the insulin preparation used at the time of admission of the case was obtained from the family doctor of these controls by using a standardised questionnaire.

\section{STATISTICAL ANALYSIS}

The study design allowed for cases and controls to be included more than once, and the data may therefore be analysed by admissions or by patients. As controls were selected from those at risk of hypoglycaemia at the time of the hypoglycaemic episode of each case ("incidence density sampling"'12) the odds ratios obtained from a matched analysis will estimate the comparative incidences of hypoglycaemia as a ratio (the rate ratio). ${ }^{1213}$ From a statistical point of view a matched analysis based on admissions (not patients) is therefore appropriate, irrespective of whether the same patient was admitted more than once. It may be argued, however, that a few patients admitted several times will have undue weight in this analysis. There- fore, the data were analysed twice-once taking all admissions and once taking only the first admission of each patient as the unit of analysis. As the results of the two approaches were similar we present here only those results from analyses based on admissions. Univariate and multivariate relative rate estimates, probability values from $\chi^{2}$ statistics, and $95 \%$ confidence intervals were calculated from matched analyses by using conditional logistic regression ${ }^{14}$ (with EGRET software). Data are presented as means (standard deviations) or proportions. Comparison of unmatched data was by Student's (unpaired) $t$ test and $\chi^{2}$ test with Yates's correction where appropriate. Time trends in admissions for hypoglycaemia were investigated by using $\chi^{2}$ tests for trend.

\section{Results}

In all, 122 admissions for hypoglycaemia among 103 patients were identified. Fifteen (12\%) admissions had been miscoded as hyperglycaemic coma. Among the cases 12 patients were admitted twice, two patients three times, and one patient four times. Table II shows that the annual number of admissions increased from 1984 to $1987\left(\mathrm{p}<0.001, \chi^{2}\right.$ test for trend).

A total of 244 control admissions in 199 patients were selected. Twenty seven patients were admitted twice, six patients three times, and two patients four times. Four patients were included as both cases and controls on different occasions.

Ten admissions for hypoglycaemia (nine patients) and 19 control admissions (17 patients) were excluded from the analysis because of missing information on insulin preparation or blood glucose control or suicidal insulin overdose (one patient). Control admissions corresponding to excluded cases were retained in the data set and analysed in a stratum with an appropriate case by using the same matching criteria. Therefore, in the analysis 112 case admissions for hypoglycaemia (94 patients) were compared with 225 control admissions (182 patients), with a ratio of controls to cases ranging from one to four. Table III gives the reasons for admission of controls

\section{CLINICAL CHARACTERISTICS OF CASE AND CONTROL} ADMISSIONS

Table IV gives the clinical characteristics of case and control admissions. Treatment with human insulin was more common in case admissions than in control admissions $(52 / 112(46 \%) v 77 / 225$ (34\%); $\mathrm{p}=0 \cdot 003)$.

TABLE II -No of admissions for hypoglycaemia in eight hospitals in canton of Berne, 1984-7

\begin{tabular}{ccc}
\hline Year & $\begin{array}{c}\text { No of admissions for } \\
\text { hypoglycaemia }\end{array}$ & Total No of admissions \\
\hline 1984 & 19 & 26982 \\
1985 & 24 & 27644 \\
1986 & 35 & 27303 \\
1987 & 44 & 27442
\end{tabular}

${ }^{\star} \mathrm{p}<0 \cdot 001 ; \chi^{2}$ test for trend

TABLE III-Reasons for admission in hospital controls

\begin{tabular}{lc}
\hline Reason & No (\%) \\
\hline Cardiovascular & $44(19 \cdot 6)$ \\
Diabetes outpatient clinic & $43(19 \cdot 1)$ \\
Ophthalmological & $36(16 \cdot 0)$ \\
Surgery & $23(10 \cdot 2)$ \\
Nephrological & $21(9 \cdot 3)$ \\
Gastroenterological & $14(6 \cdot 2)$ \\
Diabetes regulation & $14(6 \cdot 2)$ \\
Oncological & $11(4 \cdot 9)$ \\
Infections & $6(2 \cdot 7)$ \\
Miscellaneous & $13(5 \cdot 8)$ \\
\hline Total & $225(100 \cdot 0)$ \\
\hline
\end{tabular}


TABLE IV-Clinical characteristics of case admissions (for hypoglycaemia) and control admissions (for other conditions). Values are numbers (percentages) of admissions unless otherwise stated

\begin{tabular}{|c|c|c|c|}
\hline & Case admissions $(n=112)$ & Control admissions $(n=225)$ & p Value * \\
\hline Mean (SD) age (years) & $\begin{array}{c}50 \cdot 2(21) \\
67 / 45\end{array}$ & $\begin{array}{l}52 \cdot 1(20) \\
144 / 81\end{array}$ & $\begin{array}{l}0 \cdot 13 \\
0 \cdot 46\end{array}$ \\
\hline $\begin{array}{l}\text { Sex }(M / F) \\
\text { Insulin preparation: }\end{array}$ & $67 / 45$ & $144 / 81$ & \\
\hline $\begin{array}{l}\text { Human } \\
\text { Animal }\end{array}$ & $\begin{array}{l}52(46) \\
60(54)\end{array}$ & $\begin{array}{r}77(34) \\
148(66)\end{array}$ & 0.003 \\
\hline $\begin{array}{l}\text { Mean }(\mathrm{SD}) \text { insulin dose } \\
(\mathrm{U} / \mathrm{kg} / \text { day })\end{array}$ & $0.59(0.24)$ & $0.61(0.25)$ & $0 \cdot 37$ \\
\hline $\begin{array}{l}\text { No of daily injections } \\
1 \\
2 \\
\geqslant 3\end{array}$ & $\begin{array}{l}44(39) \\
59(53) \\
9(8)\end{array}$ & $\begin{array}{r}95(42) \\
113(50) \\
17(8)\end{array}$ & $0 \cdot 20$ \\
\hline $\begin{array}{l}\text { Onset of diabetes: } \\
\text { Early } \\
\text { Late }\end{array}$ & $\begin{array}{l}54(48) \\
58(52)\end{array}$ & $\begin{array}{r}97(43) \\
128(57)\end{array}$ & $0 \cdot 58$ \\
\hline $\begin{array}{l}\text { Mean (SD) duration of } \\
\text { diabetes (years) }\end{array}$ & $15 \cdot 3(10)$ & $17 \cdot 5(9)$ & 0.15 \\
\hline $\begin{array}{l}\text { Glycaemic control: } \\
\text { Good } \\
\text { Acceptable }\end{array}$ & $\begin{array}{l}18(16) \\
44(39)\end{array}$ & $\begin{array}{l}20(9) \\
68(30)\end{array}$ & 0.016 \\
\hline $\begin{array}{l}\text { Fair } \\
\text { Poor }\end{array}$ & $\begin{array}{l}31(28) \\
19(17)\end{array}$ & $\begin{array}{l}66(29) \\
71(32)\end{array}$ & 0010 \\
\hline $\begin{array}{l}\text { History of hypoglycaemic coma: } \\
\text { Yes }\end{array}$ & $58(52)$ & $\begin{array}{r}43(19) \\
182(81)\end{array}$ & $<0.0001$ \\
\hline $\begin{array}{l}\text { No } \\
\text { Mean (SD) body mass index } \\
\left(\mathrm{kg} / \mathrm{m}^{2}\right)\end{array}$ & $23 \cdot 1(3 \cdot 5)$ & $24 \cdot 1(4 \cdot 2)$ & $0 \cdot 11$ \\
\hline
\end{tabular}

$\star$ Probabilities from univariate conditional logistic regression analysis.

Of the human insulins taken, $87 \%$ (112) were semisynthetic preparations and $13 \%$ (17) insulin made by recombinant DNA techniques. In all, $80 \%$ (103) of admissions taking human insulins were taking human Actrapid or human Monotard. A total of $116(90 \%)$ of the admissions taking human insulin had previously taken animal insulin. The exact time of transfer to human insulin could be ascertained in $65 \%(17 / 26)$ of patients who were not treated with Actrapid or Monotard but in only 38\% (39/103) of patients who were taking either of these insulins. The average number of months of taking human insulin was $11 \cdot 6$ for case admissions and $11 \cdot 1$ for control admissions. Animal insulins were of porcine $(125 / 208 ; 60 \%)$, beef/ porcine $(81 / 208 ; 39 \%)$, or beef $(2 / 208 ; 1 \%)$ origin. All insulins were highly purified, with a proinsulin content of less than one part per million.

Most patients were receiving conventional insulin treatment with one or two daily injections. Nine cases and six controls used a pen injector. Glycaemic control was better in cases than in controls. In patients with measurements of glycated haemoglobin $\mathrm{A}_{1}$ mean (SD) values were $9 \cdot 40 \%(1 \cdot 84 \%)$ in cases $(n=38)$ and $11 \cdot 00 \%$

TABLE V-Characteristics of admissions for hypoglycaemia who were treated with human insulin or animal insulin. Values are numbers (percentages) of case admissions unless otherwise stated

\begin{tabular}{|c|c|c|c|}
\hline & $\begin{array}{l}\text { Cases treated with } \\
\text { human insulin }\end{array}$ & $\begin{array}{l}\text { Cases treated with } \\
\text { animal insulin }\end{array}$ & $\mathrm{p}$ Value \\
\hline \multicolumn{4}{|l|}{ Glycaemic control: } \\
\hline Good & $7(13)$ & $11(18)$ & \multirow{4}{*}{0.50} \\
\hline Acceptable & $24(46)$ & $20(33)$ & \\
\hline Fair & $12(23)$ & $19(32)$ & \\
\hline Poor & $9(17)$ & $10(17)$ & \\
\hline \multicolumn{4}{|l|}{ History of hypoglycaemic coma: } \\
\hline Yes & $27(52)$ & $31(52)$ & \multirow{2}{*}{0.87} \\
\hline No & $25(48)$ & $29(48)$ & \\
\hline \multicolumn{4}{|l|}{ Onset of diabetes: } \\
\hline Early & $26(50)$ & $28(47)$ & \multirow[t]{2}{*}{0.87} \\
\hline Late & $26(50)$ & $32(53)$ & \\
\hline \multicolumn{4}{|l|}{ Mean (SD) duration of } \\
\hline \multicolumn{3}{|l|}{ Mean (SD) insulin dose } & $0 \cdot 32$ \\
\hline \multicolumn{3}{|l|}{ Mean (SD) body mass index } & 0.089 \\
\hline \multicolumn{4}{|l|}{ Clinical presentation: } \\
\hline No coma & $7(13)$ & $10(17)$ & \\
\hline Uncomplicated coma & $27(52)$ & $40(66)$ & \\
\hline Complicated coma: & & & $0.079 \star$ \\
\hline Pyramidal signs & $5(10)$ & $1(2)$ & \\
\hline Seizure & $12(23)$ & $9(15)$ & \\
\hline Death & $1(2)$ & $0(0)$ & \\
\hline
\end{tabular}

${ }^{\star} \chi^{2}$ Test comparing complicated coma admissions with all other admissions for hypoglycaemia.
$(2 \cdot 64 \%)$ in controls $(n=56)$. Corresponding values for haemoglobin $A_{1 c}$ were $8.08 \%(1 \cdot 34 \%)$ in cases $(n=17)$ and $8.47 \%(1.89 \%)$ in controls $(\mathrm{n}=52)$, and mean blood glucose concentration was $9.88(3.69) \mathrm{mmol} / \mathrm{l}$ in cases $(n=57)$ and $11.54(3.95) \mathrm{mmol} / \mathrm{l}$ in controls $(\mathrm{n}=$ 117). Frequency of treatment with $\beta$ blockers was similar among cases and controls. Eight $(7 \cdot 1 \%)$ and 22 $(10 \%)$ case and control admissions respectively were taking a $\beta$ blocker $(p=0 \cdot 5)$.

\section{CLINICAL CHARACTERISTICS OF CASE ADMISSIONS}

Table $\mathrm{V}$ gives the characteristics of human and animal insulin treated hypoglycaemia admissions. Blood glucose control was comparable in the two groups. They were also similar with respect to previous episodes of severe hypoglycaemia, onset of diabetes, body mass index, and insulin dose. Duration of diabetes was shorter in those treated with human insulin, although this was no longer apparent when only the $43(83 \%)$ of admissions in patients who had been transferred to human insulin were considered. There was a trend towards more severe episodes of hypoglycaemia with human insulin. Seventeen (33\%) admissions treated with human insulin were admitted with coma complicated by seizure or pyramidal signs, as compared with $10(17 \%)$ treated with animal insulin $(p=0 \cdot 079)$. There were no deaths among the patients treated with animal insulin and one death in the group treated with human insulin (this patient has been described in detail elsewhere ${ }^{2}$.

TABLE VI-Case-control analysis ${ }^{\star}$ of risk factors for severe hypoglycaemia based on cases and hospital controls

\begin{tabular}{|c|c|c|}
\hline & $\begin{array}{l}\text { Unadjusted rate ratio } \\
\text { (95\% confidence } \\
\text { interval) }\end{array}$ & $\begin{array}{c}\text { Adjusted rate ratio } \\
\text { (95\% confidence } \\
\text { interval) }\end{array}$ \\
\hline \multicolumn{3}{|c|}{ Insulin preparation: } \\
\hline Human & $2 \cdot 4(1 \cdot 3$ to $4 \cdot 4)$ & $3.0(1.4$ to 6.4$)$ \\
\hline Animal $†$ & 1.0 & \\
\hline \multicolumn{3}{|c|}{ Glycaemic control: } \\
\hline Poort & $1 \cdot 0$ & $1 \cdot 0$ \\
\hline Fair & $1.6(0.8$ to 3.2$)$ & $1 \cdot 3(0.6$ to $3 \cdot 1)$ \\
\hline Acceptable & $2 \cdot 3(1 \cdot 2$ to $4 \cdot 4)$ & $2.9(1.3$ to $6 \cdot 3)$ \\
\hline Good & $3.9(1.4$ to 7.5$)$ & $2 \cdot 9(1 \cdot 1$ to $7 \cdot 7)$ \\
\hline \multicolumn{3}{|c|}{ History of hypoglycaemic coma: } \\
\hline Yes & $3 \cdot 8(2 \cdot 3$ to $6 \cdot 4)$ & $4 \cdot 6(2 \cdot 5$ to $8 \cdot 6)$ \\
\hline Not & $1 \cdot 0$ & 1.0 \\
\hline \multicolumn{3}{|c|}{ Onset of diabetes: } \\
\hline Early & $1.2(0.6$ to 2.5$)$ & $2 \cdot 0(0.7$ to 5.3$)$ \\
\hline Late $\dagger$ & 1.0 & 1.0 \\
\hline
\end{tabular}

*Analysis is based on 112 cases and 225 hospital controls matched for age, sex, and date of admission by using conditional logistic regression. Multivariate estimates are adjusted for all variables listed and for duration of diabetes and body mass index. †Reference.

\section{ANALYSIS OF RISK FACTORS}

Table VI gives the relative rate estimates obtained from univariate and multivariate analysis based on comparisons between case admissions and control admissions. The univariate analysis results in an estimated 2.4-fold higher rate of admission for hypoglycaemia $(95 \%$ confidence interval 1.3 to 4.4$)$ in those treated with human insulin compared with those treated with animal insulin. With increasing degree of blood glucose control the rate ratio increased from 1.0 in the baseline "poor control" category, through 1.6 $(0.8$ to 3.2$)$ in the "fair" category, $2.3(1.2$ to 4.4$)$ in the "acceptable" category, to $3.9(1.4$ to 7.5$)$ in the "good" category (test for trend, $p=0.001$ ). The rate in patients with a history of hypoglycaemic coma was $3 \cdot 8$ (2.3 to 6.4) times higher than that in patients with no such history. Patients with early onset of diabetes had a higher rate than patients with late onset, although this difference was not significant.

The multivariate analysis did not markedly alter these results. The rate ratios associated with human insulin, history of hypoglycaemia, and early onset of diabetes increased whereas those associated with 
differing degrees of diabetes control mostly decreased. The trend for increased rate of hypoglycaemia with better glycaemic control remained $(p=0 \cdot 003)$. These results did not change when hospital of admission was included in the model or when the 13 admissions (10\% of admissions taking human insulin) who were not transferred to human insulin but who had been treated with human insulin since diagnosis of diabetes were excluded.

\section{ANALYSIS BY YEAR}

The effect associated with human insulin was strongly related to the year of hospital admission (table VII). In 1984 none of the study patients were treated with human insulin. In 1985 one out of 23 cases and six out of 40 controls were treated with human insulin, but the rate ratio did not reach significance. In 1986 and 1987, however, use of human insulin was significantly more common in case admissions than in control admissions, resulting in estimated rate ratios of about three in 1986 and four in 1987.

\section{DIABETES ASSOCIATION CONTROLS}

Among the Swiss Diabetic Association controls the prevalence of use of human insulin in 1987 was $56 \%$ (48/86) compared with $77 \%$ (33/43) among the cases admitted in 1987. The univariate analysis resulted in a relative rate of $2 \cdot 2(95 \%$ confidence interval $1 \cdot 1$ to $4 \cdot 8)$. This is smaller than the estimate of 3.98 obtained with the hospital controls in 1987 (table VII), although the confidence limits clearly overlap.

\section{Discussion}

In the canton of Berne the number of hospital admissions of insulin treated diabetic patients for severe hypoglycaemia to eight representative hospitals rose from 19 (70/100000 admissions) in 1984 to 44 $(160 / 100000)$ in 1987 . This increase occurred in parallel with the introduction of human insulin. Our case-control study suggests that there is an association between use of human insulin and hospital admission for severe hypoglycaemia. Several potential biases, however, need to be considered before the results of the study can be accepted as showing a potentially serious drawback to the use of human insulin in diabetes.

In clinical practice the decision to change a patient's treatment to human insulin could be influenced by their previous experience of hypoglycaemia. If patients at increased risk of hypoglycaemia are more likely to have their treatment changed to human insulin this could lead to an apparent higher risk of hypoglycaemia in patients taking human insulin. In this study such selection bias is unlikely to have occurred. In the period investigated patients were generally transferred to human insulin purely because of the non-availability of their porcine preparation. The decision to change treatment was therefore not influenced by clinical criteria. The repeat prescriptions held by patients detailed the trade name of the insulin (for example, Actrapid or Monotard), and at some stage when the patients attended the pharmacy to collect their insulin

TABLE VII-Analysis by year of rate of admission for hypoglycaemia in patients taking human insulin compared with patients taking animal insulin

\begin{tabular}{lcccc}
\hline & 1984 & 1985 & 1986 & 1987 \\
\hline Use of human insulin (\% (proportion) of patients): & $0(0 / 51)$ & $11(7 / 63)$ & $44(36 / 81)$ & $61(86 / 142)$ \\
$\quad$ All admissions & $0(0 / 16)$ & $4(1 / 23)$ & $60(18 / 30)$ & $77(33 / 43)$ \\
Case admissions & $0(0 / 35)$ & $15(6 / 40)$ & $35(18 / 51)$ & $54(53 / 99)$ \\
Control admissions & & $0 \cdot 23(0 \cdot 03$ to $2 \cdot 1)$ & $3 \cdot 02(1 \cdot 1$ to $8 \cdot 6)$ & $3 \cdot 98(1 \cdot 5$ to $10 \cdot 4)$ \\
Rate ratio* (95\% confidence interval) & &
\end{tabular}

*Human insulin compared with animal insulin. Univariate estimates were estimated by using conditional logistic regression. they would be given the human rather than the porcine form. Clinical evaluation of the patients did not play a part in this process. This is reflected by the fact that the time when the patients were transferred to human insulin was often not known to their doctor. That selective transfer of high risk patients to human insulin did not occur is also supported by the finding that a history of hypoglycaemic coma was no commoner among those admitted for hypoglycaemia who had been taking human insulin than those admitted for hypoglycaemia who had been taking animal insulin.

Because those admitted to hospital represent only a small proportion of all patients with severe hypoglycaemia, ${ }^{15}$ admission bias must also be considered. If patients taking human insulin were more likely to be admitted to hospital when they developed hypoglycaemia than patients taking animal insulin, and if the same was not true for presentation of controls at hospital for other conditions, then a spurious apparent association between human insulin and hypoglycaemia could be generated. As transfer to human insulin was generally not influenced by patient characteristics it is unlikely that the propensity of patients to be referred to hospital for hypoglycaemia was related to the insulin preparation used. Furthermore, if patients taking human insulin were more likely to be admitted for a given episode of hypoglycaemia then the average severity of hypoglycaemia should be less in those taking human insulin. In fact, the tendency was for the reverse, with those taking human insulin being admitted with more severe hypoglycaemia. Admission bias does not therefore seem to provide an adequate explanation of the findings

The comparison with the Swiss Diabetic Association control group also yielded a significant association between use of human insulin and hypoglycaemia. This comparison is not susceptible to bias due to patients taking human insulin having a lesser tendency to present with the conditions of the controls than patients taking animal insulin.

The possibility that the increased risk associated with human insulin could be accounted for by confounding by other risk factors for hypoglycaemia was assessed through multivariate adjustment for these factors. Such adjustments increased the relative rate of hypoglycaemia associated with use of human insulin. It is therefore improbable that the limited ability of such multivariate methods to control for confounding ${ }^{16} 17$ could account for the findings. Other factors associated with the use of human insulin, which were not assessed in our study, could possibly account for the findings. Such factors would have to be important risk factors for hypoglycaemia and be strongly associated with human insulin use to explain the relative rate of severe hypoglycaemia of 3.0 for human insulin. It seems unlikely that such a factor was missed in this study. Also, it is difficult to see how this confounding could have arisen, given the apparent lack of bias in the selection of cases and controls

The results of this study, together with the close temporal relation seen between increasing use of human insulin and the rise in the number of cases of severe hypoglycaemia, suggest that human insulin should be considered a potential risk factor for severe hypoglycaemia. To our knowledge this is the only study specifically designed to investigate the risk of hypoglycaemia during the transition to human insulin. Crossover trials comparing efficacy and safety of human and porcine insulin in small numbers of patients have shown that comparable blood glucose control is attained with similar doses of human and porcine insulin. ${ }^{18-20}$ No important difference in the occurrence of hypoglycaemia was evident, although in one trial three out of 94 patients withdrew because of severe or frequent hypoglycaemia during treatment 
with human insulin. ${ }^{18}$ The diabetes control and complications trial is a large ongoing randomised trial studying the effect of intensive insulin treatment versus conventional treatment on vascular complications in insulin dependent diabetes mellitus. ${ }^{21}$ Type of insulin preparation was not a randomised variable in this trial. Over time the incidence of severe hypoglycaemia among the study cohort decreased by $50 \%$, despite the increasing use of human insulin. On those grounds it was argued that no safety concern relating to human insulin was evident ${ }^{22}$ However, the criteria for inclusion into the trial were modified during its course. Patients with a history of severe hypoglycaemia or with hypoglycaemia without warning symptoms became ineligible for the study. ${ }^{23}$ Our data confirm that these patients are at high risk of further episodes of severe hypoglycaemia. ${ }^{2425}$ The patients recruited into the study during its later stages would thus be expected to be at lower risk of hypoglycaemia, and the falling rate of severe hypoglycaemia could be purely due to changes in the eligibility criteria. Therefore, the trial's data relating to severe hypoglycaemia cannot be considered as evidence against an increased risk of severe hypoglycaemia in patients transferred to human insulin.

Routine mortality data for diabetic patients have also been examined in an attempt to assess whether changes in risk of death from hypoglycaemia have occurred. ${ }^{20}$ These data are unreliable in many respects. Diabetes is often not mentioned on death certificates, the coding system does not differentiate between insulin treated diabetes and non-insulin treated diabetes, and patients with hypoglycaemic coma may, as shown in this study, be miscoded as having hyperglycaemic coma.

The pathophysiological mechanism underlying the observed increase in the risk of severe hypoglycaemia after transfer to human insulin is unclear. Human insulin may impair awareness of hypoglycaemia. Our accompanying paper in this issue ( $\mathrm{p} 622$ ), which reports the results of a randomised double blind crossover trial, shows that neuroglycopenic symptoms are more common hypoglycaemic symptoms in patients taking human insulin as compared with those taking porcine insulin..$^{27}$

This case-control study confirms that strict blood glucose control with human insulin is a risk factor for severe hypoglycaemia. This result is similar to that obtained in the diabetes control and complications trial, ${ }^{21}$ in which the rate of severe hypoglycaemic reactions in the intensively treated group was $54 \cdot 1 / 100$ person years as compared with $17 \cdot 4 / 100$ person years in the control group. The resulting rate ratio of $3 \cdot 1$ is comparable with the adjusted value of $2 \cdot 9$, which in the present study was associated with good glycaemic control.

Age at onset of diabetes was not significantly related to risk of hypoglycaemia, nor did cases have diabetes of longer duration than controls. Cases and controls were therefore matched for age and sex and, to some extent, also for duration and age at onset of diabetes. The high proportion of men and of patients with onset before age 30 among cases nevertheless suggests that, as previously shown, ${ }^{2425}$ male patients and patients with insulin dependent diabetes are at increased risk of hypoglycaemia.

In conclusion, our study offers evidence that transfer to human insulin may increase the risk of severe hypoglycaemia. Patients' treatment should be changed only under a doctor's guidance, and not in the pharmacy because their porcine preparations have become unavailable. As human insulin in general has no advantages over highly purified animal insulin $\mathrm{s}^{28}$ the costs and benefits of universal transfer to human insulin should be seriously considered.

We thank the medical directors of the participating hospitals; all collaborating physicians and pharmacists; and Dr J Stutz, medical head of VESKA. We also thank Yoav Ben-Shlomo, Lucy Carpenter, Stuart Logan, Michael Marmot, Paul McKeigue, Geoffrey Rose, Martin Shipley, Peter Smith, and Judith Stephenson for comments on an earlier draft. Finally, we thank Mrs S Scheidegger, who was responsible for much of the data collection.

1 Berger WG, Althaus BU. Reduced awareness of hypoglycemia after changing from porcine to human insulin in IDDM. Diabetes Care 1987;10:260-1.

2 Teuscher A, Berger WG. Hypoglycaemia unawareness in diabetics transferre to human insulin. Lancet 1987; ;i:382-5.

3 Hepburn DA, Eadington DW, Patrick AW, Colledge NR, Frier BM. Symptomatic awareness of hypoglycaemia: does it change on transfer from anima to human insulin? Diabetic Med 1989;6:586-90.

4 Berger WG, Keller U, Honegger B, Jaeggi E. Warning symptoms of hypoglycaemia during treatment with human and porcine insulin in diabetes mellitus. Lancet 1989;i:1041-4.

5 Heine RJ, van der Heyden EAP, van der Veen EA. Responses to human and porcine insulin in healthy subjects. Lancet 1989;ii:946-8.

6 Cryer PE. Human insulin and hypoglycemia unawareness. Diabetes Care 1990;13:536-7.

7 Egger M Teuscher A Berger W. Hypoglycaemia unawareness: human vs animal insulin. Diabetologia 1988;31:453-4.

8 Schlesselman JJ. Sample size requirements in cohort and case-control studies of disease. Am $\mathcal{F}$ Epidemiol 1974;99:381-4.

9 Medizinische Statistik VESKA. Projektbeschrieb für die Diagnosen- und Operationsstatistik. Aarau, Switzerland: Vereinigung Schweizer Krankenhäuser (VESKA), 1983.

10 Rifkin H, ed. Physician's guide to noninsulin-dependent (type II) diabetes: diagnosis and treatment. 2nd ed. Alexandria, Virginia: American Diabetes Association, 1988

11 Sackett DL. Bias in analytic research. $\mathcal{F}$ Chronic Dis 1979;32:51-68.

12 Greenland S, Thomas DC. On the need for the rare disease assumption in casecontrol studies. Am F Epidemiol 1982;116:547-53.

13 Rodrigues L, Kirkwood BR. Case-control designs in the study of common diseases: updates on the demise of the rare disease assumption and the choice of sampling scheme for controls. Int f Epidemiol 1990;19:205-13.

14 Hosmer DW, Lemeshow S. Applied logistic regression. New York: John Wiley, 1989.

15 Potter J, Clarke P, Gale EAM, Dave SH, Tattersall RB. Insulin-induced hypoglycaemia in an accident and emergency department: the tip of an iceberg? BMf 1982;285:1180-2.

16 Davey Smith G, Phillips A. Declaring independence: why we should be cautious. I Epidemiol Commun Health 1990;44:257-8.

17 Phillips AN, Davey Smith G. How independent are "independent" effects? Relative risk estimates when correlated exposures are measured imprecisely. $f$ Clin Epidemiol (in press)

18 Clark AJL, Adenivi-Jones RO, Knight G, Lemper JM, Wiles PG, Jones RH, et al. Biosynthetic human insulin in the treatment of diabetes. Lance 1982;ii:354-7.

19 Peacock I, Tattersall RB, Taylor A, et al. Effects of new insulins on insulin and C-peptide antibodies, insulin dose, and diabetic control. Lancet 1983;

20 Home PD, Mann NP, Hutchison AS, Pork R, Walford S, Murphy M, et al: A fifteen month double-blind cross-over trial of the efficacy and antigenicity of human and pork insulins. Diabetic Med 1984;1:93-8.

21 The DCCT Research Group. Diabetes control and complications tria (DCCT): results from the feasibility study. Diabetes Care 1987;10:1-19.

22 Gorden PH. Human insulin and hypoglycemia. $N$ Engl f Med 1990;322: $1007-8$

23 DCCT Research Group. Diabetes control and complications trial (DCCT). Update. Diabetes Care 1990;13:427-33.

24 Casparie AF, Elving LD. Severe hypoglycemia in diabetic patients: frequency, causes, prevention. Diabetes Care 1985;8:141-5.

25 Nilsson A, Tideholm BO, Kalen J, Katcman P. Incidence of severe hypoglycaemia and its causes in insulin-treated diabetics. Acta Med Scand 1988;224:257-62.

26 Stephenson J, Fuller J. Hypoglycaemia as cause of death in human insulin era. Lancet 1990;335:661.

27 Egger M, Davey Smith G, Teuscher AU, Teuscher A. Influence of human insulin on symptoms and awareness of hypoglycaemia: a randomised double 列

28 Pickup J. Human insulin. BMF 1986;292:155-7.

(Accepted 7 August 1991) 